\title{
Hexamethonium, Hypertension, and Pharmaceutical Innovation: The Transformation of an Experimental Drug in Post-war Britain
}

Link to publication record in Manchester Research Explorer

Citation for published version (APA):

Timmermann, C., \& Anderson, J. (Ed.) (2006). Hexamethonium, Hypertension, and Pharmaceutical Innovation: The Transformation of an Experimental Drug in Post-war Britain. In Devices and Designs: Medical Technologies in Hist. Perspective (pp. 156-174). Palgrave Macmillan Ltd.

Published in:

Devices and Designs: Medical Technologies in Hist. Perspective

\section{Citing this paper}

Please note that where the full-text provided on Manchester Research Explorer is the Author Accepted Manuscript or Proof version this may differ from the final Published version. If citing, it is advised that you check and use the publisher's definitive version.

\section{General rights}

Copyright and moral rights for the publications made accessible in the Research Explorer are retained by the authors and/or other copyright owners and it is a condition of accessing publications that users recognise and abide by the legal requirements associated with these rights.

\section{Takedown policy}

If you believe that this document breaches copyright please refer to the University of Manchester's Takedown Procedures [http://man.ac.uk/04Y6Bo] or contact uml.scholarlycommunications@manchester.ac.uk providing relevant details, so we can investigate your claim.

\section{OPEN ACCESS}




\section{PREPRINT}

The transformation of an experimental drug: hexamethonium, hypertension and pharmaceutical innovation in post-war Britain

CARSTEN TIMMERMANN

Centre for the History of Science, Technology and Medicine

University of Manchester

Simon Building

Manchester M13 9PL

carsten.timmermann@,manchester.ac.uk

Published in: C. Timmermann \& J. Anderson (eds), Devices and Designs: Medical Technologies in Historical Perspective (Palgrave Macmillan 2006), 156-174. 


\title{
The transformation of an experimental drug: hexamethonium, hypertension and pharmaceutical innovation in post-war Britain
}

\author{
CARSTEN TIMMERMANN
}

University of Manchester

\section{Introduction}

Hypertension is one of the most common medical problems in the developed world. ${ }^{1}$ It is also one of those modern conditions that we do not find discussed in old medical textbooks, and hypertension has not always been self-evidently viewed as a disease. ${ }^{2}$ High blood pressure has variously been interpreted, for example, as a physiological response to ageing, a metaphor for life under the strains of modernity, or the symptom of a so far unrecognised underlying genetic disease. Only in the last five decades it has become acceptable to treat high blood pressure, the symptom, without knowing the causes. Thanks to a new measuring technology (the familiar combination of an inflatable cuff, a sphygmomanometer and a stethoscope), blood pressure was accessible outside the laboratory since the early twentieth century, but the method was initially not taken up widely by physicians, and in Britain such reluctance prevailed until after World War II. ${ }^{3}$ In the US, in contrast, medical directors in the life insurance industry were quick to realise the potential of using this portable technology extensively, leading to the drawing up of tables that associated blood pressure with insurance risks. Their calculations made blood pressure interesting to epidemiologists and visible to a wider audience of physicians. ${ }^{4}$ In Britain, hypertension gained profile as an issue of medical interest immediately after World War II. This coincided with the introduction of the National Health Service (NHS) in 1948. More importantly, though, the post-war years also saw a strengthened and pro-active MRC that sought to set new standards for clinical research, a re-orientation in the pharmaceutical industry with a stronger focus on research and development, and not least the development of the first drugs that targeted high blood pressure. ${ }^{5}$ These new drugs and the constellation around the introduction of new 
treatment methods for high blood pressure, roughly between 1948 and 1960, coinciding with what has often been described as a 'golden age' of modern medicine, are the subject of this chapter. ${ }^{6}$

I will explore how hypertension was transformed into a treatable disease when a new class of drugs, the ganglion blockers, moved from the laboratory to the bedside and eventually turned from experimental tools into routine treatment, by looking at the roles played by researchers in laboratories and clinics, and the debates over practical (and to some degree ethical) issues of the long-term administration of antihypertensive drugs. The sources from which I am reconstructing this story (mostly files from the archives of the Medical Research Council, hereafter MRC) also allow me some more general statements about the dynamics of biomedicine in Britain and the interactions between the public sector and the drug companies in this crucial period. The ganglion blockers are among the fruits of the MRC's intense campaign for the establishment of a new form of academic medicine in the country. Pharmaceutical companies, as we will see, initially played subordinate roles, while the MRC pulled the strings. ${ }^{7}$ Whereas in the United States, as Nicolas Rasmussen has shown, drug companies actively approached and recruited medical academics, the story I will tell is one of 'shy' drug company representatives, recruited by the MRC for its plans. ${ }^{8}$ Only in the mid-1950s, when consensus was emerging that some forms of hypertension benefited from long-term drug treatment, as Viviane Quirke has shown for ICI, pharmaceutical companies became more proactive in the search for new antihypertensive drugs. ${ }^{9}$ Hexamethonium and other ganglion blockers prepared this consensus. But the first responses to proposals to use hexamethonium as a routine drug were cautious, and I will demonstrate how important the development of an effective system for managing its effects, both desired and undesired, with nurse-technicians and patients playing important parts alongside clinicians, was for the successful transformation of the drug. This clinical setup for the treatment of high blood pressure with hexamethonium was devised, as we will see, by a British clinician with strong MRC links, but on the other side of the globe, in a teaching hospital in New Zealand. For the first stage of our journey following the ganglion blockers from the laboratory to the clinic, however, we are now turning to the physiology laboratories of Cambridge, England, and Cambridge, Massachusetts. 


\section{Quaternary ammonium salts: From the physiology lab into the medicine cabinet}

In the 1940s, the quaternary ammonium salts soon to be known as ganglion blockers were longstanding tools for physiological research. Pharmacologists and physiologists, notably the members of the Cambridge school of physiology had been interested in these drugs because some of their effects on experimental animals resembled those of the nerve poison curare. Their main focus of interest was not the clinical application of the drugs; they were studying the molecular mechanisms of the nervous system. The blood pressure lowering effect of some of these compounds, especially tetraethylammonium (TEA) had been noted on a few occasions by researchers, but none of them had seen it as particularly significant. ${ }^{10}$ The name, ganglion blocking drugs, and the clinical potential of these compounds was a product of academic research on TEA by two young physiologists, George Acheson and Gordon Moe at Harvard Medical School in 1945 and 1946. Prompted by a pre-war article, Moe and Acheson purchased a sample of the bromide salt of TEA from Eastman Kodak, and found that its effects in an animal experiment were pharmacologically interesting. To explain these effects, Moe suggested that the TEA ion blocked the ganglia of the autonomic nervous system, the wiring, as it were, that controlled the unconscious, regulatory functions of the body.

So far our drug has not left the laboratory. But what distinguished Acheson and Moe from the researchers had had previously used quaternary ammonium compounds was the fact that they found it worthwhile to explore possible clinical applications for TEA. While some of the earlier researchers suggested there might be clinical uses for these drugs, none had considered the long-term treatment of high blood pressure a worthwhile application. 'The major ideas that Gordon Moe and I arrived at in 1943 and 1944 were already in the literature. Why then,' George Acheson asked in 1975, 'did our work make a splash whereas theirs did not? ${ }^{31}$ To Acheson, what made the difference was the fact that during World War II the physiology lab and the clinic had become far more closely linked, and that researchers had lost their reservations against talking to the pharmaceutical industry. Moe and Acheson collaborated both with clinicians and with industry and Acheson explicitly credits the post-war context 
for this change. Drugs were gaining a better status among doctors, as a result of the success of sulfonamides and penicillin, he remembers, and drug companies had become 'more respectable'. ${ }^{12}$

Acheson and Moe initiated clinical tests for TEA, but they were not very successful. The effects of the drug did not last long enough and, while the tests established the notion of ganglion blockade as a possibility, TEA was not the drug that could move smoothly from bench to bedside. The first ganglion blockers that were to prove clinically useful were the methonium compounds, and for this part of the story we are now moving to Britain. As was the case for TEA, the observation that methonium compounds had an effect on blood pressure was partly a serendipitous discovery, a byproduct of work that had its roots in the Cambridge physiological-pharmacological tradition, combined with a heightened sensitivity for cardiovascular effects in the post-war years. That hexamethonium was going to turn into a high blood pressure drug, though, was by no means obvious when the physiologist William Paton came across the methonium compounds. He was working at the time in Henry Dale's old laboratory at the MRC's National Institute for Medical Research (NIMR) at Hampstead, where researchers were just about to revert from war research to peace-time activities. Paton himself was about to turn into a respiratory physiologist. ${ }^{13}$ Paton, son of a clergyman, had studied physiology at Oxford and like many other pioneers of medical research at this time, studied medicine at University College Hospital (UCH) Medical School, where he came into contact with the MRC style of medical research. ${ }^{14}$ He joined the staff at the NIMR in 1944. In 1952 he moved to UCH for two years as Reader, a joint appointment between Rosenheim's Medical Unit and the Department of Pharmacology. From 1954 to 1959 he held a professorship of pharmacology at the Royal College of Surgeons, before succeeding J.H. Burn on the Oxford chair of Pharmacology. Hexamethonium entered the scene when Paton's laboratory at the NIMR - not for the first time - took on some work for the Institute's Division of Biological Standards. They were asked to look at the toxicity of a promising antibiotic substance, lichenoformin that a member of the Chemotherapy Division, R.K. Callow, had isolated from cultures of Bacillus licheniformis. Injecting the substance into an anaesthetised cat Paton found that nothing happened for about 25 seconds, when he measured an abrupt and transient fall in blood 
pressure. The substance seemed to trigger the release of a vasodilator (a substance that dilates blood vessels), most likely histamine, in a way that impressed Paton and his colleagues because 'it was such an interesting and clean response. ${ }^{, 15}$ The excitement over clean and pure responses was typical among pharmacologists and indicative of their ideal of reducing a drug's action, if possible, to one active principle, the interaction between a chemical structure and a physiological function. Clinical usefulness, however, as we will see later, depended on more than just understanding the mechanism of a drug. ${ }^{16}$

Callow told Paton and his colleagues more about the chemical structure of lichenoformin, and they went upstairs to the NIMR's Chemistry Division under Harold King, where they obtained a range of substances with related chemical groups, in many of whom they found that they also released histamine and triggered a similar 'delayed repressor response'. Such responses had been observed before, but according to Paton 'it was entrancing to see this simple, specific response, to detect a coherent pattern emerging in the relationship between chemical structure and pharmacological response, and to see possible new approaches to the physiology of histamine. ${ }^{17}$ The series of compounds they tested also contained two derivatives of the methonium series, C8 and C16 (the figure stands for the number of atoms in the carbon chain between the two quaternary ammonium groups). C8 produced a somewhat different, but also remarkably clean response. It proved to be a potent neuromuscular blocking agent, a drug that led to temporary paralysis, with potential applications for anaesthesia and surgery.

The decision to further pursue work on this group of substances was informed by the growing interest in developing synthetic drugs with curare-like action, to treat convulsions and as muscle relaxants for surgery. King had long been researching the active principle of curare. A significant factor was the arrival of Paton's co-worker, Eleanor Zaimis, who was experienced in chemistry as well as pharmacology. Encouraged by King, Paton and Zaimis decided to undertake a study of the whole series of methonium compounds and their effects, with carbon chain lengths from C2 to C12. Around the time when they started this work, Paton and Zaimis discovered that Ing and Barlow at Oxford were studying the same compounds, in a more systematic way and as one among a number of other 
homologous series, in an attempt to establish the structure-action relationships of neuromuscular block. ${ }^{18}$ In 1948, both groups arranged a simultaneous publication (as Letters to the Editor) in the journal Nature. It is noteworthy that effects on blood pressure were mentioned in neither paper. ${ }^{19}$ Such effects had been noticed, however. Paton and his colleagues injected the drug into a number of laboratory animals, which revealed that $\mathrm{C} 5$ and $\mathrm{C} 6$, the compounds most active in anaesthetised cats, had significant effects on the animals' blood pressures. ${ }^{20}$ Injected into a rabbit's ears, they made the ears flush in a bright red. According to his reminiscences (published in 1982), this reminded Paton of a lecture he had attended as an undergraduate on Claude Bernard's experiments on the effects of interrupting the sympathetic innervation to the rabbit's ear, pointing towards the sympathetic ganglia as a site of action of C5 and C6. This may well be a retrospectively constructed memory, but it illustrates Paton's interpretation of the ganglion blockers as the culmination of a longstanding, great tradition in physiology. Again, Paton marvelled over the 'very clean action' of the drug. ${ }^{21}$ 'The analysis of hexamethonium's action,' he remembers, 'was a most enjoyable experience. ${ }^{22}$

There was some interest in the drug's possible use as anti-hypertensive, mostly due to Acheson and Moe's series of articles two years earlier on TEA and its effect on blood pressure and an increasingly lively debate over the aetiology and treatment of hypertension. In his reminiscences Paton remembers that: 'At all events with this, and with the experience of sympathectomy, the possibility that hexamethonium might be usable in hypertension as a clean, specific ganglion blocker was one to consider. ${ }^{23}$ At the time, however, the methonium compounds to Paton and Zaimis were above all interesting pharmacological research tools. Only in a further letter to Nature in November 1948 they suggested - in one brief sentence at the end of the paper - that C6 'offers possibilities of clinical usefulness in such fields as hypertension and vascular disease, whenever tetraethylammonium iodide has too brief or slight an action.' In the following section we will see what it took to establish uses for the clean, specific responses that Paton observed in his laboratory in the much messier world of the clinic. Here too, the MRC and the networks that the Council created to promote its model of medical research played decisive roles. 


\section{Clinical trials and invisible industrialists}

The MRC appointed Paton to chair an informal committee investigating possible clinical uses of the methonium drugs. ${ }^{24}$ Along with Frank Green, the Council's Chief Medical Officer, Paton was the main correspondent in all matters concerning clinical uses of the methonium compounds (he also prepared the official report on the drugs). ${ }^{25}$ Not long after Paton and Zaimis heroically tested the effects of several methonium compounds on themselves at Westminster Hospital, together with the anaesthetist Geoffrey Organe, the MRC initiated the first clinical study of pentamethonium for the treatment of hypertension. ${ }^{26}$ The Lancet published the results in August $1948 .^{27}$ The investigation was carried out, 'at the request of the Medical Research Council', by P. Arnold and Max Rosenberg of the Medical Unit at University College Hospital, where Rosenberg had succeeded Thomas R. Elliott on what was the first, MRC-funded, full-time chairs for clinical research in Britain. ${ }^{28}$ They reported that 'pentamethonium iodide has an action similar to that of tetraethylammonium chloride, but it is effective in smaller doses' and that 'an excessive fall in blood-pressure has been the only serious toxic effect so far observed'. ${ }^{29}$ Anaesthetists experimented with hexamethonium as an antidote to the muscle relaxant decamethonium and viewed blood pressure reduction as an undesired side effect: 'In the very first case it seemed that the ensuing hypotension might be severe enough to be fatal. ${ }^{30}$ It is not obvious from these early publications that soon the lowering of blood pressure would be discussed as the main rather than a dangerous side effect of ganglion blockers. During an MRC Conference on Clinical Tests of Methonium Drugs on 22 June 1950, hypertension was one among several possible indications including use in anaesthesia and in the treatment of stomach ulcers. ${ }^{31}$

The initial responses to the methonium compounds and the suggestion that they might provide a useful treatment option for high blood pressure were cautious. Increasingly, though, they were cautiously optimistic. A series of articles reporting results of studies, involving rather small numbers of patients for today's standards, were published in the Lancet in 1950. So were reports on other antihypertensive treatments, all relatively new, such as the Kempner Rice Diet or a variety of surgical procedures. Some authors characterized the effect of hexamethonium as 'medical sympathectomy'. ${ }^{32}$ 
Sympathectomy was an irreversible surgical intervention where connections in the sympathetic nervous system of patients with malignant hypertension were severed. ${ }^{33}$

Representative of the early, cautiously positive responses was that by Stephanie Saville, reporting on a study undertaken at St Martin's Hospital, Bath, in a well-established clinic for hypertension, where the customary treatment over years had been rest in bed, sedation, and regular venesection, to which 'many patients failed to respond significantly or to maintain initial improvement'. Five cases of malignant hypertension were experimentally treated with pentamethonium, starting in December 1949, initially in the hospital and later also as outpatients. The aim was to lower the blood pressure enough to relieve symptoms without provoking others due to hypotension. While Saville was reluctant to predict the final outcome, she observed that 'none of the five cases sufficiently treated to date has failed to obtain relief from symptoms'. Saville's conclusion: 'The results in 5 patients suggest that pentamethonium bromide may be useful in the treatment of at least some forms of hypertension. ${ }^{34}$ Allan Campbell and Eric Robertson at the Royal Alexandra Infirmary, Paisley found (in a study with 8 patients) that 'hexamethonium seems to provide a useful method of reducing the blood pressure in severe hypertension with ready administration and relative freedom from toxicity. ${ }^{35}$ The main problem was finding the right dosage, and some of the side effects were quite drastic, too. R. Turner in Edinburgh suggested that 'methonium drugs have as yet no place in the routine management of patients, though they may prove useful in the treatment of resistant symptoms related to hypertension. We need more information about their precise action, and for the present it will be most profitable to study, in detail, patients who might otherwise be treated by sympathectomy. ${ }^{36}$

These clinical studies on the methonium compounds were initiated by the MRC and not, as we would expect today and as even some insiders assumed, by the pharmaceutical industry. ${ }^{37}$ Austin Doyle, a colleague of Smirk projects today's patterns of drug development on the past in his reminiscences, suggesting that May and Baker approached clinicians with the request to test the methonium compounds in the clinic. ${ }^{38}$ The files in the National Archives tell a different story, one where the MRC pulled the strings in the crucial period between 1948 and 1952, with Paton as 
unofficial patron of the ganglion blockers, supported and backed by Frank Green. The ganglion blockers provide us with an example for a major pharmaceutical innovation that had its origins in the public sector, with the industry playing a subordinate role. The Council mediated between the clinical researchers and the companies that provided the drugs, which included Wellcome Burroughs, Allen \& Hanbury's, and more often than the others, May \& Baker. Like TEA, the methonium compounds were not patent protected, and the drugs from different producers were different only with regard to preparation and sometimes purity. The MRC acted as a booster for the methonium drugs and a 'matchmaker' between clinical researchers and drug manufacturers, who assumed, it seems, that it was improper for them to approach the researchers directly. A memo by Green in 1950 illustrates the mechanics of this interaction and the central role of the Council:

I telephoned to Dr Forgan [of May \& Baker] to ask him to send supplies of pentamethonium and hexamethonium for trial by the mouth in cases of hypertension. Forgan said he would be glad to do so. He asked whether it would be in order for him to invite Rosenheim to express an opinion on the relative effects of these two substances, as May \& Baker have the impression that hexamethonium is so much more useful than pentamethonium that the latter may be on its way out. I said that there would be no objection whatever from our point of view to his asking Rosenheim this or any other question which occurred to him. (Note: May \& Bakers still seem to be under the erroneous impression that the Council, when they arrange clinical trials, prohibit the manufacturers from communicating directly with the investigator; this arrangement applied in the early days of the Therapeutic Trials Committee, but it has long since been abandoned as both unpopular and inefficient.) $)^{39}$

In the same memo, Green noted that he had suggested to Forgan that May \& Baker should look into the possible uses of the methonium drugs in ulcerative colitis, and proposed to contact a number of suitable clinical investigators for such questions and organise a conference, with Paton as secretary. On a different occasion Green wrote to Paton that 
[W] should certainly not regard it as improper for the firm of Geigy - or, indeed, any other firm - to approach Kay and Smith direct on a scientific question such as you mention. Of course, there is no obligation on Kay and Smith to assist Geigy with advice unless they like to do so. ${ }^{40}$ The power relationships, it seems, were distinctly different from those that Nick Rasmussen has described for the United States, where he finds patterns of company-funded clinical research very similar to today's as early as the inter-war period. ${ }^{41}$

\section{Therapeutic enthusiasm}

Although the MRC sought to promote the ganglion blockers, the initial responses from clinicians involved in the early clinical trials were cautious. In order to understand the transformation of hexamethonium from experimental drug to routine treatment for malignant hypertension, in this section we will look at the role of clinicians such as Frederick Horace Smirk, who we might want to call 'therapeutic enthusiasts'. ${ }^{42}$ Smirk may seem a somewhat marginal figure at the first glance. Looking closer at his career, though, it becomes clear that his department at University of Otago Medical School in Dunedin, New Zealand was modelled on the MRC-funded units run by T.R. Elliot and Thomas Lewis at University College Hospital (UCH) London in the interwar years. 'The clinic', Smirk stated in a report on his hypertension clinic in Dunedin, 'has served both research and routine requirements and often there has been no distinction between these requirements'. ${ }^{43}$ A product of the work there was, besides a routine method of treating hypertension with drugs, a major textbook on High Arterial Pressure. ${ }^{44}$ Dunedin became a satellite of clinical research in the British metropolis, and in this was not so different from British provincial universities.

Smirk, the son of a Lancashire schoolmaster, had attended Manchester University in the early 1920s, graduating MB, ChB with first class honors in 1925. He acquired his MD in 1927. After junior posts at Manchester Royal Infirmary, a Dickenson Travelling Scholarship from the MRC allowed him to go to Vienna and a Beit Memorial Medical Research Fellowship to join T.R. Elliot's unit at UCH. As Smirk's Dunedin colleague F.N. Fastier put it, UCH 'was an almost inevitable choice for tenure of the 
Beit Fellowship. No other British medical school could have provided during the 1930s a more stimulating environment for those "new men" who were intent on fusing the skills of the laboratory and the clinic. ${ }^{, 45}$ The 'new men' who joined the research staff at UCH with a Beit fellowship included eminent figures such as George Pickering or John McMichael, who would play an important role later in Smirk's career and in the hexamethonium story. ${ }^{46}$

While many of his contemporaries found positions in Britain, often full-time posts in the new research units established by the MRC, Smirk's next move after teaching appointments in the departments of pharmacology and medicine at $\mathrm{UCH}$ was to the chair of pharmacology at Cairo University in 1935. He stayed in Cairo for four years, during which he turned to the search for drugs that had an effect on blood pressure, screening nearly 1,500 commercially available chemicals in stray dogs, with little success. In 1940 he was appointed to the first full-time chair of medicine at Otago, replacing the part-time professors of systematic and clinical medicine who had retired the previous year. The move towards full-time professors who were expected to do research seemed to parallel what was happening in Britain. Later Smirk was able to link Dunedin to the metropolis in other ways. He was a scientific entrepreneur who managed to secure funding for his work from a variety of sources, including pharmaceutical companies. This success was undoubtedly due to his great enthusiasm for pharmaceutical solutions and his success in turning the ganglion blockers into routine drugs. He is also credited with the development, by selective inbreeding, of laboratory rats with inherited hypertension. ${ }^{47}$ The greatest coup of his career as research administrator, however, was to secure $£ 120,000$ from the Wellcome Trust for a completely new clinical research institute in Dunedin in 1960, then among the biggest grants the Trust had ever made. This was undoubtedly helped by the fact that McMichael by then was a Wellcome Trustee and Green the Trust's Medical Secretary.

Initially, however, the war years did not make it easy to establish a functioning laboratory in Dunedin. There was hardly any equipment and much had to be improvised, supplies were unreliable, and there was not much space for Smirk and his staff. Furthermore, Smirk was faced with a heavy teaching and administrative load. Like Paton's at the NIMR, Smirk's research turned to typical war- 
time tasks, such as the study of nitrogen mustards and the search for a pharmaceutical treatment for shock suitable for situations where quick fluid replacements were not possible. After the end of the war he returned to the search for antihypertensive drugs. This search received a boost when in 1949 he spent a sabbatical at the Postgraduate Medical School at Hammersmith Hospital in London, where McMichael was director and professor of medicine, the year when Paton, Zaimis and Organe, and later, more importantly, Arnold and Rosenheim, Elliot's successor at UCH, published the first results of their experiments with pentamethonium and hexamethonium in humans. ${ }^{48}$ Smirk, who received supplies of the drugs from May and Baker when he returned to New Zealand, it seems, had found the compounds he was looking for.

An important problem of the methonium compounds which accounted for much of the scepticism by clinicians who had tested them was their low solubility in water and the resulting low (and unreliable) rate with which the drugs were absorbed into the bloodstream when taken by mouth. Smirk overcame this by devising a regimen of subcutaneous injection, a management solution very similar to the administration of insulin to diabetics. Patients had to be 'titrated', the right dose found for each individual patient, and this dose adjusted as patient bodies got used to the drug. As the Hull physician Edmond Murphy (who characerised Smirk's attitude towards hexamethonium as 'enthusiastic') observed, 'Smirk and Alstad [one of Smirk's co-workers in Dunedin] claimed that with adequate parenteral doses - each patient being a law unto himself - a lowered tension can be maintained indefinitely'. ${ }^{49}$ This went along with a strict monitoring regime. Austin Doyle, who joined Smirk's department in 1952, remembers:

Having been working in a traditional way in a British hospital, I was amazed at the confident and routine way that these difficult drugs were being used.... Patients would arrive at the clinic at about 8:30 AM, have blood pressures recorded while seated and standing, and be given a dose of hexamethonium subcutaneously by the nurse. Blood pressures were then recorded in both postures at 30-minute intervals throughout the day. At about 12:30 PM Smirk would visit the clinic, look at the data, and order the appropriate afternoon doses. Patients would attend daily 
until the correct dose had been attained and would then be allowed to leave, having been supplied with tuberculin syringes, needles, and multidose containers of the drug, which they had been trained to use. ${ }^{50}$

The multidose containers had been prepared at the university's pharmacology department by dissolving bulk supplies provided by May and Baker. Some years later, such multidose vials were available prepacked, directly from the drug producers.

\section{Drugs and discipline}

Hexamethonium, it seems, disciplined doctors, patients, carers, and technicians alike. 'It is most important', Smirk stated in his account of the practices in the hypertension clinic, 'that the patient should understand something of the working of the drug, and in our experience the technician is invaluable in educating patients, and any special points she cannot answer can be dealt with when the doctor comes round ${ }^{51}$ He was passionate enough about the importance of his technicians that a passage referring to the women is capitalised in his report:

THERE IS ONE ESSENTIAL WITHOUT WHICH OUR CLINIC COULD NOT

FUNCTION EFFECTIVELY, AND THIS IS THE PRESENCE OF RELIABLE

TECHNICIANS INTERESTED IN THEIR WORK AND WITH SUFFICIENT STABILITY, FRIENDLINESS AND POISE TO BE TRUSTED BY THE PATIENTS. WITH

INTELLIGENT GIRLS WHO ARE KEEN TO LEARN WE HAVE EXPERIENCED NO

DIFFICULTY WHATSOEVER IN OBTAINING FROM THEM ACCURATE PRESSURE

READINGS AND COMMENTS ON CORRESPONDING SYMPTOMS, IF ANY. ${ }^{52}$

Smirk devised a treatment manual for patients and carers that explained the reasons for the treatment, suggested ways of dealing with the possible side effects of the drugs, which would disappear soon if patients co-operated and played active parts in the therapy, and warned of the possible consequences of non-compliance or interruption of the treatment. ${ }^{53}$ Smirk explained patients that ${ }^{\mathrm{C}}[\mathrm{t}]$ he object of treatment is to decrease the risk of complications of high blood pressure such as heart failure and 
stroke, and secondly to relieve symptoms such as headache and breathlessness in cases where these are due to high blood pressure.${ }^{54}$ Patients were encouraged to perform simple tests on themselves, which relied on them developing an awareness of the effects of the drug on their bodies. The 'standing test' took advantage of one of the most common side effects of hexamethonium, postural hypotension, a sudden lowering of the blood pressure when patients stood up, which led to dizziness. 'Almost all of our well-trained patients can tell the doctor from their own subjective sensations whether a given dose is producing a considerable fall of the blood pressure', as Smirk reports. 'Intelligent and co-operative patients have been entrusted with the fine adjustment of their dose ${ }^{35}$ The ways in which Smirk's practices dealt with postural hypotension and even made use of this side effect, even more than the issue of resorption, indicate that even a difficult drug could be managed.

Figure 1: These beds, raised to compensate for postural hypotension, are examples of the simple solutions used in Smirk's clinic for the management of side effects. Figures from F.H. Smirk, The Treatment of High Blood Pressure (Edinburgh: Royal College of Physicians, 1956). I am grateful to the Royal College of Physicians of Edinburgh for granting me permission to reproduce these images.

Smirk blamed the bad results that other clinical researchers reported with the methonium drugs, as Green wrote in a letter to Paton, on "ffaulty technique", namely lack of proper ancillary care of the patients'. ${ }^{56}$ Smirk's practices involved patients as well as technicians and nurses in active and responsible roles. Tending to the psychology of the patients was part of the regime: 'It is well to remember that nervous tension, worry, quarrels, excitement and adverse emotion lead to elevation of the blood pressure', Smirk wrote. 'It is a part of treatment to lessen such troubles. ${ }^{57}$ How was this done? 'Reassurance by doctor and technician that the milder side effects are in no sense dangerous and will probably disappear anyhow usually leads to a happier frame of mind. ${ }^{58}$ As important, it seems, was the company of other patients. Patients would sit together in groups of four while undergoing their 
lengthy tests, exchanging experiences, and there was 'something of the atmosphere of a club about the clinic' ${ }^{59}$ Not all were happy, though: 'It is well to realise ... that a drug which, in a proportion of patients, causes side effects will get the blame for all sorts of incidental illness. ${ }^{60}$ Frank Green, after his visit in New Zealand, reported to Paton:

I talked to some of his patients under treatment in the wards, and I think it is fair to say that I got the impression that their enthusiasm for hexamethonium therapy is not quite so great as his. Not unnaturally, they dislike the side effects. If, however, as Smirk says, it is possible to keep patients with malignant hypertension alive and reasonably comfortable for periods at least of several years, then that does represent an important advance in therapy. ${ }^{61}$

To be fair, though, the patients who Green met were most likely newly admitted patients who had not yet been 'trained'.

\section{Conclusion}

A Lancet editorial in 1951 supports Green's conclusions, stating that: 'Early reports leave no doubt that the methonium compounds are the most powerful hypotensive agents yet developed. ${ }^{62}$ Other therapeutic enthusiasts, like Edward Freis were quick to acknowledge this. ${ }^{63}$ By the end of the 1950s, hypertension was transformed into a treatable disease. The ganglion blockers, along with the routines designed by Smirk and his colleagues, had come to form a relatively standardized package that circulated easily and that paved the way for new, more specific antihypertensive drugs. Drug therapy for hypertension had returned from the more remote parts of the British Empire to the metropolis. Green and Paton felt that the MRC had done what it could do for the methonium compounds in 1952, when they felt that these drugs no longer needed boosting. ${ }^{64}$ Their emphasis was clearly on research rather than commercial exploitation; for the Council hexamethonium was part of a long-standing campaign to establish their concept of biomedicine as the dominant form of medical research in Britain, in the clinic as well as the preclinical sciences. Commercial exploitation followed, however, with several drug companies developing their own, patent-protected ganglion blockers on the back of the success 
with the methonium compounds. Examples are May and Baker's Gaplegin, or Pendiomide, which was developed and marketed by both Ciba and ICI more or less simultaneously. The new ganglion blockers were not necessarily better antihypertensives than hexamethonium, but they were more easily absorbed by the gut and therefore more reliable when taken by mouth, and therefore disposed with the need for elaborate clinical setups like that developed by Smirk. ${ }^{65}$ For several producers, the ganglion blockers provided stepping stones into the new field of pharmaceuticals for blood pressure control. ${ }^{66}$

Modern drug research, we assume, aims to find drugs for specific targets. In the case of hypertension the target was defined and refined as new drugs became available. Drugs like the ganglion blockers and other medicines for chronic 'disorders' have also come to redefine our lifeworld, and particularly notions of what we consider as normal or as pathological. Hypertension in the late 1940s was not what it is today. Malignant hypertension, seriously increased blood pressure which led to lifethreatening, pathological changes, today has more or less disappeared from the industrialised world. Starting with the ganglion blockers, new drugs turned hypertension from an acute into a chronic disease that could be managed (rather than cured) and allowed sufferers to lead reasonably normal lives (in a way that was similar to the role that insulin played for diabetic patients). But more than that, the ganglion blockers paved the way for a new therapeutic enthusiasm. In the case of hypertension it has become acceptable, even recommended, to treat a symptom-less physiological phenomenon, as if it were a disease.

\section{Acknowledgements}

Many friends and colleagues have commented on this paper or earlier versions during its long period of gestation, including panel members and audiences at workshops in London, Durham and Manchester, a conference in Vienna, and a seminar in London. I especially thank my Manchester colleagues Emm Barnes, John Pickstone and Elizabeth Toon for their valuable suggestions on the final draft. The research for the paper was generously supported by the Wellcome Trust. 


\section{Notes}

${ }^{1}$ T.E. Kottke, R.J. Stroebel, R.S. Hofman, 'JNC 7 - It's more than high blood pressure', Journal of the American Medical Association, 289 (2003), 2573-5.

${ }^{2}$ Cf. C. Timmermann, 'To Treat or Not to Treat: Drug Research and the Changing Nature of Essential Hypertension', in: T. Schlich, U. Tröhler, eds, The Risks of Medical Innovation: Risk Perception and Assessment in Historical Context (London: Routledge, 2006); idem, 'A Matter of Degree: The Normalisation of Hypertension, circa 1940 - 2000', in: W. Ernst, ed., Histories of the Normal and the Abnormal (London: Routledge, 2006); I.H. Page, Hypertension Research: A Memoir 1920-1960 (New York: Pergamon Press, 1988); G.W. Pickering, High Blood Pressure (London: Churchill, 1955).

${ }^{3}$ Cf N. Postel-Vinay, A Century of Arterial Hypertension 1896-1996 (Chichester: Wiley, 1996); K. Ilsley, An historical study of arterial blood pressure and its management, from the seventeenth century to modern times (MA dissertation: University of Wales Swansea, 2005). On attitudes of British physicians towards experimental methods, see C. Lawrence, 'Still Incommunicable: Clinical Holists and Medical Knowledge in Interwar Britain', in: C. Lawrence, G. Weisz, eds, Greater than the Parts. Holism in Biomedicine 1920-1950 (New York \& Oxford: Oxford University Press, 1998), 94-111.

${ }^{4}$ See, for example, D. Riesman, 'High Blood Pressure and Longevity', Journal of the American Medical Association, 96 (1931), 1105-11. As Rothstein, Davis and others have shown, the life insurance industry in the US assumed many of the functions of public health authorities in Europe. W.G. Rothstein, Public Health and the Risk Factor: A History of an Uneven Medical Revolution (Rochester: University of Rochester Press, 2003); A. B. Davis, 'Life Insurance and the Physical Examination: A chapter in the rise of American medical technology,' Bulletin of the History of Medicine, 55 (1981), 392-406.

${ }^{5}$ C. Timmermann, 'Clinical Research in Post-War Britain: The Role of the Medical Research Council', in: C. Hannaway, ed., Biomedicine in the Twentieth Century: Practices, Policies and Politics (forthcoming); J. Austoker, L. Bryder, eds, Historical Perspectives on the Role of the MRC (Oxford: Oxford University Press, 
1989); C.C. Booth, 'From Art to Science: The story of clinical research,' in: A Physician Reflects: Herman Boerhaave and other Essays (London: Wellcome Trust Centre for the History of Medicine at UCL, 2003), 79-101; C.C. Booth, 'Clinical Research,' in: W.F. Bynum, R. Porter, eds., Companion Encyclopedia of the History of Medicine (London \& New York: Routledge, 1993), 205-229.

${ }^{6}$ Cf. A.M. Brandt, M. Gardner, 'The golden Age of Medicine?’ in: R. Cooter, J. Pickstone, eds, Companion to Medicine in the Twentieth Century (London: Routledge, 2003), 21-37.

${ }^{7}$ On interactions between science and industry, see J.-P. Gaudilliere and I. Löwy, eds, The Invisible Industrialist: Manufactures and the Production of Scientific Knowledge (Houndmills: Macmillan, 1998).

${ }^{8}$ N. Rasmussen, 'The Drug Industry and Clinical Research in Interwar America: Three Types of Physician Collaborator', Bulletin of the History of Medicine, 79 (2005), 50-80; idem, 'The Moral Economy of the Drug Company-Medical Scientist Collaboration in Interwar America', Social Studies of Science, 34 (2004), 161-85.

${ }^{9}$ Cf. V. Quirke, 'From Evidence to Market: Alfred Spinks's 1953 survey of fields for pharmacological research, and the origins of ICI's cardiovascular programme', in V. Berridge, K. Loughlin, eds, Producing Health: medicine, the market and the mass media in the twentieth century (London: Routledge, 2005), 144-169.

${ }^{10}$ G.H. Acheson, 'Tetraethylammonium, Ganglionic Blocking Agents, and the Development of Antihypertensive Therapy', Perspectives in Biology and Medicine, 19 (1975), 136-148.

${ }^{11}$ Acheson, 'Tetraethylammonium', p. 146.

${ }^{12}$ Acheson, 'Tetraethylammonium'.

${ }^{13}$ W. D. M. Paton, 'Hexamethonium', British Journal of Clinical Pharmacology, 13 (1982), 7-14. See also H.P. Rang, P. Walton, 'Sir William Drummond MacDonald Paton, CBE, 5 May 1917-17 October 1993', Biographical Memoirs of Fellows of the Royal Society, 42 (1996), 290-314. Paton's laboratory notebooks can be consulted in the Wellcome Library for the History and the Public Understanding of Medicine, PP/WDP/C/1/2. On the NIMR, see Austoker and Bryder, eds, Historical Perspectives, pp. 35-57.

${ }^{14}$ Timmermann, 'Clinical Research'. 
${ }^{15}$ Paton, 'Hexamethonium', pp. 7-8. See also Paton Laboratory Notebooks, Wellcome Library, $\mathrm{PP} / \mathrm{WDP} / \mathrm{C} / 1 / 2$.

${ }^{16}$ Beta blockers are a good example. According to the original physiological theory explaining their action, they should not have lowered blood pressure. Cf. Timmermann, 'To Treat or not to Treat'; V. Quirke, 'Putting Theory into Practice: James Black, Receptor Theory and the Development of the Beta-Blockers at ICI, 1958-1978,' Medical History, 50 (2006), 69-92.

${ }^{17}$ Paton, 'Hexamethonium', p. 8.

${ }^{18}$ Paton noted later that 'Barlow and Ing have never at any time either looked for or been interested in the ganglionic actions of this series'. Paton to Green, 19 July 1950, UK National Archives (hereafter UK NA), FD1/1172.

${ }^{19}$ R. B. Barlow, H. R. Ing, 'Curare-like Action of Polymethylene bis-Quaternary Ammonium Salts', Nature 161 (1948), 718; W. D. M. Paton, E. J. Zaimis, 'Curare-like Action of Polymethylene bisQuaternary Ammonium Salts', Nature 161 (1948), 718-9.

${ }^{20}$ Laboratory notebooks, Wellcome Library, PP/WDP/C/1/2.

${ }^{21}$ Paton, 'Hexamethonium', p. 10.

${ }^{22}$ Ibid.

${ }^{23}$ Ibid., p. 11.

${ }^{24}$ FD1/1172, UK NA.

${ }^{25}$ 'The Methonium Compounds' (typescript), Paton Papers, PP/WDP/C6, Wellcome Library.

${ }^{26}$ G. Organe, W.D.M. Paton, E.J. Zaimis, 'Preliminary Trials of Bismethylammonium Decane and Pentane Diiodide (C10 and C5) in Man', Lancet, 253 (1949), 21.

${ }^{27}$ P. Arnold, M.L. Rosenheim, 'Effect of Pentamethonium Iodide on Normal and Hypertensive Persons', Lancet, 254 (1949), 321-3.

${ }^{28}$ Ibid.

${ }^{29}$ Ibid. 
${ }^{30}$ A.R. Hunter, 'Hexamethonium Bromide', Lancet, 255 (1950), 251-2, p. 252.

${ }^{31}$ Conference on Clinical Tests of Methonium Drugs, 22 June 1950, Minutes of the Meeting, UK NA, FD1/1172.

${ }^{32}$ R. Turner, “'Medical Sympathectomy” in Hypertension: a clinical study of methonium compounds', Lancet, 256 (1950), 353-8. See also M.L. Rosenheim, 'Lability of Blood Pressure', Lectures on the Scientific Basis of Medicine, 1951-52, 1 (1953), 96-115. On the rice diet, see 'Diet in Hypertension [editorial]', Lancet, 255 (1950), 549-60; 'Rice Diet in Hypertension [editorial]', Lancet, 256 (1950), 529-30. The MRC organized a study of the effects of the rice diet: D.R. Cameron, D.M. Dunlop, R. Platt, M.L.

Rosenheim, E.P. Sharpey-Schaffer, 'The Rice Diet in the Treatment of Hypertension: A report to the Medical Research Council', Lancet, 256 (1950), 509-13.

${ }^{33}$ See R. Platt, S.W. Stanbury, 'Sympathectomy in Hypertension', Lancet, 255 (1950), 659-9;

'Sympathectomy in Hypertension [editorial]', Lancet, 255 (1950), 768-9.

${ }^{34}$ S. Saville, 'Pentamethonium in Hypertension', Lancet, 256 (1950), 358-60.

${ }^{35}$ A. Campbell, E. Robertson, 'Treatment of Severe Hypertension with Hexamethonium Bromide’, British Medical Journal, 256 (1950), 804-6.

${ }^{36}$ R. Turner, “Medical Sympathectomy” in Hypertension: a clinical study of methonium compounds', Lancet, 256 (1950), 353-8.

${ }^{37}$ Minutes of a meeting on clinical tests of methonium drugs held on 19 July 1950, UK NA, FD1/1172.

${ }^{38}$ A.E. Doyle, 'Sir Horace Smirk: Pioneer in Drug Treatment of Hypertension', Hypertension, 17 (1991), 247-250, p. 249. Doyle joined Smirk’s department in 1952.

${ }^{39}$ Memo, probably by Green, 27 Sept 1950, UK NA, FD1/1172.

${ }^{40}$ Green to Paton, 4 October 1950, UK NA, FD1/1172.

${ }^{41}$ Rasmussen, 'The Drug Industry and Clinical Research'; idem, 'The Moral Economy of the Drug Company-Medical Scientist Collaboration'. 
${ }^{42}$ Another therapeutic enthusiast was Edward Freis in the US, who later organised the large-scale treatment trials for hypertension with the Veterans Association Hospitals.

${ }^{43}$ F.H. Smirk, ‘Organisation of a Hypertensive Clinic, More Particularly For Patients On Methonium Treatment', October 1951, typescript, UK NA, FD1/1172, p. 4.

${ }^{44}$ F.H. Smirk, High Arterial Pressure (Oxford: Blackwell, 1957).

${ }^{45}$ F.N. Fastier, 'Biography: Sir Horace Smirk: Professor Emeritus', New Zealand Medical Journal, 67 (1968), 258-65, p. 258.

${ }^{46}$ On clinical science in Britain, see Booth, 'Clinical Research' and idem, 'From Art to Science'.

${ }^{47}$ F.H. Smirk, W.H. Hall, 'Inherited Hypertension in Rats,' Nature, 182 (1958), 727-728.

${ }^{48}$ Organe, Paton, Zaimis, 'Preliminary Trials’; P. Arnold, M.L. Rosenheim, 'Effect of Pentamethonium Iodide on Normal and Hypertensive Persons', Lancet, 254 (1949), 321-323.

${ }^{49}$ E.A. Murphy, 'Treatment of Hypertension with Hexamethonium Bromide', Lancet, 258 (1951), 899901.

${ }^{50}$ Doyle, 'Sir Horace Smirk', pp. 249-250

${ }^{51}$ F.H. Smirk, 'Organisation of a Hypertensive Clinic’, p. 5.

${ }^{52}$ Ibid, p. 4.

${ }^{53}$ F.H. Smirk, 'Instructions for Patients on C6 Injections', October 1951, typescript, UK NA, FD1/1172. On compliance, see J. Greene, "Therapeutic Infidelities: "Noncompliance” Enters the Medical Literature, 1955-1975', Social History of Medicine, 17 (2004), 327-343.

${ }^{54}$ Smirk, 'Instructions for Patients on C6 Injections', p. 1.

${ }^{55}$ Smirk, 'Organisation of a Hypertensive Clinic', p. 7.

${ }^{56}$ Green to Paton, 25 April 1952, UK NA, FD1/1172.

${ }^{57}$ Smirk, 'Organisation of a Hypertensive Clinic', p. 9.

${ }^{58}$ Ibid.

${ }^{59}$ Ibid. 
${ }^{60}$ Ibid.

${ }^{61}$ Green to Paton, 25 April 1952, UK NA, FD1/1172.

62 'Methonium and Hypertension [editorial], Lancet, 257 (1951), 395-6, p. 395.

${ }^{63}$ E.D. Freis, 'Methonium Compounds in Hypertension [letter]', Lancet, 257 (1951), 909.

${ }^{64}$ Paton to Green, 28 April 1952, UK NA, FD1/1172.

${ }^{65}$ F.H. Smirk, 'Hypotensive Actions of Hexamethonium Bromide and some of its Homologues: Their Use in High Blood-Pressure', Lancet, 260 (1952), 1002-5.

${ }^{66}$ See, for example, K.H. Beyer, 'Chlorothiazide’, British Journal of Clinical Pharmacology, 13 (1982), 15-24. See also Quirke, 'From Evidence to Market'. 